\title{
OSAS'ı Hastalarda Temporomandibular Eklem Rahatsızlıklarının Prevelansının Değerlendirilmesi
}

\section{Evaluation of Prevalence of Temporomandibular Joint Disorders in Patients with OSAS

\author{
$\underline{\text { Saim }}$ YANIK $^{1}{ }^{1 D}$, Mehmet Emrah POLAT ${ }^{1}$ (D) , Zafer Hasan Ali SAK ${ }^{2}$
}

\begin{abstract}
1 Harran Üniversitesi Diş Hekimliği Fakültesi Ağız Diş ve Çene Cerrahisi Anabilim Dalı, Şanlıurfa, Türkiye
\end{abstract} 2 Harran Üniversitesi Tıp Hekimliği Fakültesi Göğüs Hastalıkları Anabilim Dalı, Şanlıurfa, Türkiye

Öz.

Amaç: Çalışmamızın amacı polisomnografi (PSG) ile Obstrüktif Uyku Apne sendromu (OSAS) teşhisi konmuş 54 hastada Temporomandibular eklem (TME) rahatsızlığı prevelansını, ve OSAS'ın yaş ve cinsiyet ile ilișkisini araştırmaktır.

Materyal ve Metod: Çalışmamıza Ocak 2018 - Haziran 2018 tarihleri arasında Harran Üniversitesi Tıp Fakültesi Göğüs Hastalıkları Anabilim Dalında OSAS teshisi konmus fakat OSAS tedavisine başlanmamı 54 hasta dâhil edildi. OSAS teşhisi konmuş hastalar Harran Üniversitesi Diş Hekimliği Fakültesi Ağız, Diş ve Çene Cerrahisi kliniğine yönlendirildi. Bu hastaların TME muayenesi tek hekim tarafından bilateral olarak yapııdı. Muayene esnasında TME rahatsızlığına bakııdı. Teşhis edilen rahatsızıklar TME rahatsızığı/eksen 1 (RDC/TMD Axis 1) sınıflandırmasına göre klasifiye edildi. Ayrıca hastaların yaş ve cinsiyetleri de kayıt edildi.

Bulgular: Elde edilen sonuçlara göre hastaların \% 75,9'u erkek, \% 24,1'i kadındır. \% 24,1'inde bruksizm, \% 9,3'ünde redüksiyonlu disk deplasmanı vardır. Apne/Hipopne indeksi (AHi) indeksine göre hastaların \% 70,4'ünde ağır derecede, \% 20,4 'ünde orta derece, \% 9,3'ünde hafif derecede OSAS bulunmaktaydı. Hastaların yaş ortalaması yaklaşık 50 , hafif derecede OSAS grubunun yas ortalaması 33,4 , orta derecede OSAS grubunun yaş ortalaması 49,3 ve ağır derecede OSAS grubunun yaş ortalaması ise 51,8 'dır. Test istatistiğinin anlamlılık değerlerine göre, hastalık derecesi ile yalnızca yaş grupları arasında istatistiksel olarak anlamlı ilişki bulunmuştur $(p<0.05)$. Coklu karşılaşırıma testi bulgularına göre ağır derecede OSAS teşhisi konulan hastaların yaş ortalamaları, hafif derecede OSAS teşhisi konulan hastalara göre anlamlı ölçüde yüksektir. Diğer tüm faktörlerle hastalık derecesi arasında istatistiksel olarak anlamlı ilişki bulunamamıştı $(p>0.05)$.

Sonuç: OSAS erkelerde ve ilerleyen yaşlarda daha yüksek oranda görülmektedir ve yaş ilerledikçe hastalığın şiddeti de artmaktadır. Çalışmamızda OSAS'ı hastalarda üçte birinde TME rahatsızığının eşlik ettiği görülmüş olup en sık gözlenen TME rahatsızlığı bruksizm olarak kaydedilmiştir. Yazarlar bunun nedeni olarak uyku kalitesinin bozulmasının hastalarda psikolojik strese yol açtığını ve sonuç olarak bruksizmi tetiklediğini düşünmektedir. Bununla birlikte çalışmanın daha geniş hasta popülasyonları üzerinde yapılmasına ve ayrıca OSAS'lı hastaların tedavi öncesi ve sonrası TME rahatsızı̆ı̆ı bulgularını karşılaştıran ileri çalışmalara intiyaç bulunmaktadır.

Anahtar Kelimeler: Temporomandibular eklem rahatsızlı̆ı̆, OSAS, Yaş, Cinsiyet

Abstract

Background: The aim of our study was to investigate the prevalence of Temporomandibular Joint (TMJ) disorder in 54 patients diagnosed with Obstructive Sleep Apnea syndrome (OSAS) by polysomnography (PSG) and to invetigate age and sex relationship.

Materials and Methods: 54 patients who were diagnosed with OSAS Between January 2018 and June 2018, in the Department of Pulmonology, Faculty of Medicine, Harran University were included in this study. Patients diagnosed with OSAS were referred to the Oral, Dental and Maxillofacial Surgery Clinic of the Faculty of Dentistry at Harran University. TME examination of these patients was performed bilaterally by the same physician. TME was examined during the examination. The diagnosed ailments were classed according to the RDC/TMD Axis 1 classification. The age and sex of the patients were also recorded.

Results: According to the results, $75.9 \%$ of the patients were male and $24.1 \%$ were female. $24.1 \%$ have bruxism and $9.3 \%$ have reduced disc displacement. According to the ahi index, $70.4 \%$ of patients had severe, $20.4 \%$ had moderate, $9.3 \%$ had mild OSAS. The mean age of the patients was approximately 50 , the mean age of the mild Osas group was 33.4 , the mean age of the moderate OSAS group was 49.3 and the mean age of the severe OSAS group was 51.8. According to the significance values of the test statistics, there was a statistically significant relationship between the degree of disease and age groups only $(p<0.05)$. The average age of patients diagnosed with severe OSAS is significantly higher than those diagnosed with mild OSAS, according to the findings of the multiple comparison test. There was no statistically significant association between all other factors and the degree of disease $(p>0.05)$.

Conclusions: OSAS is more common in men and in later ages, and the severity of the disease increases as age progresses. In our study, TME disorder was observed in one third of patients with OSAS and bruxism was recorded as the most common TME disorder group. The authors consider this to be due to impaired sleep quality leading to psychological stress in patients and consequently triggering bruxism. However, the study needs to be carried out on the wider patient population and further studies comparing the findings of TME disease before and after treatment of patients with OSAS are needed.

Key words: Temporomandibular joint diseases, OSAS, Age, Sex

\section{Sorumlu Yazar I \\ Corresponding Author}

Saim YANIK

Harran Üniversitesi

Diş Hekimliği Fakültesi

Ağız Diş ve Çene Cerrahisi Anabilim

Dalı, 63300, Şanlıurfa

e-mail: saimyanik@hotmail.com

Geliş tarihi / Received:

28.11.2019

Kabul tarihi / Accepted: 21.02.2020

DOI: 10.35440/hutfd.652214 


\section{Giriş}

Temporomandibular eklem (TME) dışkulak yolunun hemen önünde yer alan, mandibular kemiğin kondili ile kafatasındaki madibular fossa arasında, menteşe ve kayma hareketi yapabilen diatrodial sinoviyal bir eklemdir ve kompleks bir yapıya sahiptir (1).

TME rahatsızlıkları toplumda sık gözlenen, çiğneme kaslarını ve TME komponentlerini içeren bir hastalık grubudur (2). Genel belirtileri kulak önü bölgesinde ve çiğneme kaslarında ağrı, çene hareketlerinde kısıtılık ve asimetri, baş ağrısı, TME bölgesinde ses ve uyku bozukluklarıdır. TME hastalıkları aynı zamanda orofasiyal bölgenin odontojen olmayan ağrılarının baş etkenidir (1).

TME rahatsızlıklarının kompleks ve çok faktörlü bir etiyolojisi vardır. Bunlar arasında, fiziksel, psikolojik ve psikososyal sebepler bulunmaktadır (3). Bu rahatsızlıkların etyolojisinde kas hiperfonksiyonu, hormonal değişiklikler, travma ve eklem ile ilişkili internal düzensizlikler rol oynamakla birlikte, cinsiyet en belirgin risk faktörüdür (3). Kadın popülasyonu, hastalığın en sık gözlendiği cinsiyet olup, 20 ila 40 yaş aralığı başlangıç yaş aralığı olarak bildirilmiş̧ir (4). TME rahatsızıı̆ı sınıflandırmak için Araştırma Tanı Kriterleri (RDC/TME rahatsızlığı) yaygın olarak kullanılmakta olup 2 değerlendirme bileşenine sahiptir. Eksen I, klinik ve radyografik bir değerlendirme olup, myo-fasiyal ağrı, disk yer değiştirme ve artralji, artrit ve artrozu ayırt etmek için, Eksen II ise, psikolojik durumu ve ağrıya bağı rahatsızlığı değerlendirir (5).

Obstrüktif Uyku Apne sendromu (OSAS) uyku periyodu boyunca tekrarlayan apne veya hipopnelerle karakterize, bu süreci takiben sıklıkla kan oksijen satürasyonunda azalma ve arousollerle seyreden bir hastalıktır. Buna bağlı olarak başta nörolojik ve kardiyovasküler olmak üzere pek çok ciddi komplikasyona yol açabilen bir durumdur (6). "Uyku apne sendromu" terimi 1973 yllında ilk kez Guilleminault (7) ve arkadaşları tarafından tıp literatüründe kullanıımış olup toplumdaki prevalansı \%30-70 arasında değişmekte$\operatorname{dir}(8)$.

OSAS'a sebep olan faktörler arasında; ileri yaş, cinsiyet, kısa kalın boyun yapısı, kraniyofasiyal anomaliler (mikrognati, retrognati gibi), obezite, sigara, alkol ve sedatif ilaç kullanımı sayılabilir $(9,10)$.

Klinik olarak OSAS'lı hastalarda en belirgin semptom horlamadır. Horlama dışında havayolunun obstrüksiyona uğraması ile gelişen apne, nokturi, gece terlemesi, gece ağız kuruluğu sık uyanma gibi gece semptomları ve baş ağrısı, gün içi aşırı uykululuk hali, konsantrasyon bozukluğu, kognitif ve duygu durum değişiklikleri gibi gündüz semptomları gözlenmektedir. Önemli sağlık problemlerine neden olabilen OSAS'ın tanısını koyabilmek için klinik değerlendirmede alınan ayrıntılı anamnez dışında biyokimyasal bir parametre bulunmamakta ve fizik muayene yetersiz kalmaktadır. Dolayısıyla tanı için klinik değerlendirmenin yanı sıra uyku ile ilişkili solunum bozukluğu varlığını objektif olarak göstermek gerekmektedir. Günümüzde hala solunum ile ilişkili uyku bozuklukları tanısında altın standart tanı testi, uyku laboratuvarında yapılan polisomnografidir (PSG) (11).

Horlama, tanıklı apne, gündüz aşııı uyku hali gibi semptomları olan hastada yapılan PSG'de apne-hipopne indeksinin (AHI) 5'in üzerinde olması tanı koydurucudur (12). Polisomnografi; OSAS tanısı ve derecesinin belirlenmesinde kullanılan önemli bir tanı yöntemi olmakla birlikte obstruktif patolojiyi sağlamaya yönelik bilgi sağlamamaktadir (13).

Yapılan bu çalışmanın amacı PSG ile OSAS teşhisi konmuş 54 hastada TME rahatsızlığı prevelansını araştırmak, yaş ve cinsiyet ilişkisine de bakmaktır.

\section{Materyal ve Metod}

Çalışmamıza Ocak 2018-Haziran 2018 tarihleri arasında Harran Üniversitesi Tıp Fakültesi Göğüs Hastalıkları Anabilim Dalında OSAS teşhisi konmuş fakat OSAS tedavisine başlanmamış 54 hasta dâhil edildi. Çalışmamıza Harran Üniversitesi Rektölüğ̈̈ Araştırma ve Uygulama Hastanesi'nden 01/07/2019-E.27762 tarih ve sayılı çalışma izni alınmıştır. Hastalara OSAS teşhisi şu şekilde konulmuştur. Harran Üniversitesi Eğitim Araştırma ve Uygulama Hastanesinde Uyku Laboratuvarında gece horlama ve/veya gündüz aşırı uykululuk belirtileri bulunan ve tüm gece polisomnografi (PSG) uygulanan 54 OSAS olgunun verileri değerlendirildi. Horlama, tanıklı apne ve gündüz aşırı uyku hali yakınmaları bulunan hastalara spontan gece uykusu ile elli beş kanallı Alice-5 Diagnostic Sleep System (Philips Respironics, Murrysville, USA) polisomnograf ile video monitorizasyonu eşliğinde, solunum ve yüzeyel bacak EMG kaydıyla tüm gece polisomnografi yapıldı, kayıtlar AASM 2 Skorlama kurallarına göre manüel olarak skorlandı. OSAS varlığı AHI ne göre her saat başı apne ve hipopne ataklarının sıklığına dayanarak belirlendi. Apne en az 10 saniye süreyle termal sensörle ölçülen hava akımı sinyalinde $\% 90$ azalması şeklinde kabul edilirken, hipopne ise en az 10 saniye süreli nazal basınç sinyalinde bazale göre $\% 30^{\prime}$ luk azalmayla oksijen satürasyonunda \%4' lük düşüş veya arousal (uyanma reaksiyonu) ile sonuçlanması yine hipopne nazal basınç sinyalinde bazale göre \% 50'lik azalmayla oksijen satürasyonunda \%3'lük düşüş veya arousal (uyanma reaksiyonu) ile sonuçlanması kabul edildi. AHI'ne göre saatte 5 'ten az olay basit horlama veya normal kabul edilirken, 5 ve daha fazla olayın gözlenmesi OSAS olarak kabul edildi. Çalışmaya alınan olgular üç gruba ayrıldı. AHI: 5-15 hafif OSAS, AHI: 16-30 orta OSAS, AHI $\geq$ 30 / saat ağır OSAS grubu kabul edildi.

OSAS teşhisi konmuş hastalar Harran Üniversitesi Diş Hekimliği Fakültesi Ağız, Diş ve Çene Cerrahisi kliniğine yönlendirildi. Bu hastaların TME muayenesi tek hekim tarafından bilateral olarak yapıldı. Muayene esnasında TME ra- 
hatsızıı̆ına bakıldı. Teşhis edilen rahatsızlıklar TME rahatsızlığı/eksen 1 sınıflandırmasına göre klasifiye edildi. Ayrıca hastaların yaş ve cinsiyetleri de kayıt edildi.

Bu çalışmanın veri analizi aşamasında frekans analizi, tanımlayıcı istatistiksel veri analizi, normallik testleri ve istatistiksel hipotez testleri kullanılmıştır. Kategorik veriler arasındaki çapraz tablo bulgularına göre hücrelerin beklenen değerleri son derece düşük olduğu durumlarda $(n<5)$, klasik ki-kare testi yerine Fisher testi uygulanmıştır. Ayrıca derece gruplarına ait karşılaştırmalarda örneklem sayısı grup bazında çok düşük olduğundan $(n<10)$ Kruskal-Wallis testi uygulanmıştır. Uygulamalar R project (R Core Team, 2019) ve IBM SPSS 22 yazııımı kullanılarak hazırlanmıştır.

\section{Bulgular}

Tablo 1 de hastaların cinsiyet, yaş ortalaması, hastalık derecesi ve redüksiyonlu disk deplasmanı arasındaki ilişki ve hastalık derecesi ve bruksizm arasındaki ilişkiye ait sonuçlar verilmiş̧ir.

Tablo 1. Hastalık grupları ve bu grupların yaş ve cinsiyete göre dağılımı.

\begin{tabular}{|c|c|c|c|c|}
\hline \multirow{5}{*}{ Yaş* } & OSAS skoru & $\mathrm{n}$ & $\begin{array}{l}\text { Yaş } \\
\text { ortalaması }\end{array}$ & $p$ \\
\hline & AHI (5-15)a & 5 & 33,400 & \multirow{4}{*}{0.021} \\
\hline & AHİ (16-30) & 11 & 49,360 & \\
\hline & AHI (>30)a & 38 & 51,840 & \\
\hline & Toplam & \multicolumn{2}{|l|}{54} & \\
\hline \multicolumn{5}{|c|}{ a: Gruplar arasında istatistiksel olarak anlamlı fark vardır. } \\
\hline \multirow{4}{*}{ Cinsiyet ** } & OSAS skoru & Erkek & Kadın & $\mathrm{p}$ \\
\hline & AHIं (5-15) & $100,00 \%(5)$ & $0,00 \%(0)$ & \multirow{4}{*}{0.345} \\
\hline & $\mathrm{AHI}(16-30)$ & $63,64 \%(7)$ & $36,36 \%(4)$ & \\
\hline & $\mathrm{AHI}(>30)$ & $76,32 \%(29)$ & $23,68 \%(9)$ & \\
\hline Toplam & 54 & 41 & 13 & \\
\hline \multirow{4}{*}{ Bruksizm** } & OSAS skoru & Yok & Var & $p$ \\
\hline & AHI (5-15) & $100,00 \%(5)$ & $0,00 \%(0)$ & \multirow{4}{*}{0.534} \\
\hline & AHI (16-30) & $72,73 \%(8)$ & $27,27 \%(3)$ & \\
\hline & AHI (>30) & $73,68 \%(28)$ & $26,32 \%(10)$ & \\
\hline Toplam & 54 & 41 & 13 & \\
\hline \multirow{4}{*}{$\begin{array}{l}\text { Redüksiyonlu } \\
\text { disk } \\
\text { deplasmanı** }\end{array}$} & OSAS skoru & Yok & Var & $\mathrm{p}$ \\
\hline & AHI (5-15) & $80,00 \%(4)$ & $20,00 \%(1)$ & \multirow{4}{*}{0.584} \\
\hline & AHI (16-30) & $90,91 \%(10)$ & $9,09 \%$ (1) & \\
\hline & $\mathrm{AHI}(>30)$ & $92,11 \%$ (35) & $7,89 \%(3)$ & \\
\hline Toplam & 54 & 49 & 5 & \\
\hline
\end{tabular}

Bu sonuçlara göre hastaların \% 75,9'u erkek, \%24,1'i kadındır. \%24,1'inde bruksizm, \%9,3'ünde redüksiyonlu disk deplasmanı vardır. AHI indeksine göre hastaların \% 70,4'ünde ağır derecede OSAS, \%20,4'ünde orta derece OSAS, \%9,3'ünde hafif derecede OSAS bulunmaktadır. Hastaların yaş ortalaması yaklaşık 50 , hafif derecede OSAS grubunun yaş ortalaması 33.400 , orta derecede OSAS grubunun yaş ortalaması 49.360 ve ağır derecede
OSAS grubunun yaş ortalaması ise 51.840 dır. Test istatistiğinin anlamlılık değerlerine göre, hastalık derecesi ile yalnızca yaş grupları arasında istatistiksel olarak anlamlı ilişki bulunmuştur $(p<0.05)$. Çoklu karşılaştırma testi (Post$\mathrm{Hoc}$ ) bulgularına göre 3 . derece olan hastaların yaş ortalamaları, 1. derece hastalara göre anlamlı̈lçüde yüksektir. Diğer tüm faktörlerle hastalık derecesi arasında istatistiksel olarak anlamlı ilişki bulunamamıştır ( $p>0.05)$.

\section{Tartışma}

TME rahatsızı̆̆ı, kas-iskelet sistemi rahatsızlıklarının bir alt grubudur ve yüz bölgesinde odontojenik kaynaklı nedenlerinden sonra en sık görülen ağrı nedenidir. TME rahatsızlığı olan kişilerin en sık şikâyeti mandibular fonksiyonun neden olduğu veya şiddetlendirdiği fasiyal veya TME bölgesinde ağrıdır. Belirtiler arasında ağız açıkığı sırasında sapma olan veya olmayan sınırlı mandibula artikülasyonu, eklem sesi, baş ağrıları ve uyku kalitesindeki değişiklikler bulunur (14). TME bozuklukları çoğunlukla kondil-artiküler disk kompleksi ve eklem yüzeylerinin yapısal uyumsuzluğu ile ilgili problemleri içerir. Çiğneme kaslarını etkileyen hastalıklar ise kas TME rahatsızlığı olarak sınıflandırıı (14). Nüfusun\% 50 ila\% 80'inin en az bir TME rahatsızlığı belirtisi veya semptomu olduğu tahmin edilmektedir. TME rahatsızlığından etkilenen bireylerin neredeyse $\% 10$ 'u tedavi gerektirmektedir, çünkü hastalık ciddi fonksiyonel kısıtlamalara (çiğneme ve ağzını açmada) ve bireyin sosyal aktiviteleri katılamamasına hatta çalışamamasına neden olabilir (15). 20 ila 50 yaş arası kadınların TME rahatsızığı nedeni ile başvuru oranı erkeklere göre beş kat daha yüksektir (15). TME rahatsılılıkları multifaktöriyel etiyolojiye sahiptir ve bir veya daha fazla faktör başlangıçta veya devamında katkıda bulunabilir. Bu faktörler arasında anatomik değişiklikler, makrotravmalar, mikrotravmalar, okluzal dengesizlikler, parafonksiyonel alışkanlıklar ve duygusal stres gibi sistemik durumlar bulunur. Bu faktörlerin her bireyde nasıl etkileşime girip TME rahatsızlığına neden olduğu hala bilinmemektedir (14). Mandibular fonksiyon ağrısına ek olarak, TME rahatsızlığı hastaları sıklıkla eklem sesi, baş ağrısı, bruxism ve zayıf, huzursuz uyku bildirmektedir (15).

Yapılan birçok çalışmada OSAS'ın TME rahatsızlıkları dâhil olmak üzere kronik ağrı bozuklukları ile ilişkili olduğunu göstermektedir. $(16,17)$. Cunali ve ark. PSG ile hafif veya orta dereceli OSAS tanısı olan 87 erişkin hastanın 32 'sinde $(\% 36,8)$ TME rahatsızlığı kriterlerine göre belirlenen TME rahatsızlığı olduğunu bildirmişlerdir. Başka bir çalışmada ise Smith ve ark. 2009, TME rahatsızlığı tabanlı miyofasiyal ağrılı 53 hastanın 11 yetişkinine (\%28) polisomnografi ile OSAS tanısı olduğunu belirtmişlerdir. Sanders ve ark. (18) 2013 yılında, diğer çalışmalardan farklı olarak yapmış oldukları OPPERA (Orofasiyal Ağrı Prospektif Değerlendirme ve Risk Değerlendirmesi) çalışmasında OSAS bulguları ile ilk başlangıç TME rahatsızlığı ve 
kronik TME rahatsızlığı arasındaki ilişkiye bakmışlar ve OSAS ile TME rahatsızığı arasında anlamlı bir ilişki olduğunu belirtmişlerdir. Yapmış olduğumuz bu çalışmada toplam 54 OSAS'ı hastanın 13'ünde bruksizm (\%24,1), 5'inde ise $(\% 9,3)$ redüksiyonlu disk deplasmanı tanısı konmuştur. OSAS'ın derecesi ile redüksiyonlu disk deplasmanı ve bruksizm arasında istatistiksel olarak anlamlı ilişki bulunamamıştır ( $p>0.05)$.

Uyku bozuklukları objektif ve subjektif ölçümler kullanılarak klinik değerlendirme ile teşhis edilebilir. Objektif ölçümlerden PSG çok önemlidir, çünkü uyku mimarisinin değerlendirilmesine izin verir. Çoğu uyku bozukluğunun teşhisinde altın standart olarak kabul edilir. PSG'de hastanın elektroensefalogramı, elektrookülogram, elektromiyogram, nazal hava akımı ve nabız oksimetrisini poligrafide kaydetmek gibi çeşitli fizyolojik ölçümler elde etmek için çeşitli yöntemler kullanır. Bununla birlikte, bu test yeterli teçhizata ve özel olarak eğitilmiş insan kaynağına sahip olmayı ve büyük finansal yatıımları gerektirdiğinden testin kullanılabilirliğini kısıtıdır.(19) Veiga ve ark. (20) uyku kalitesi TME rahatsızlığı arasındaki ilişkiyi inceleyen yayınlar üzerinde yaptıkları derlemede 13 adet yayına ulaşabildikleri ve bu yayınlardan 8 inin anket, 3 ünün nonstandardize sorular ve sadece ikisinde PSG kullandığını belirtmiştir. Yapmış olduğumuz bu araştırma çalışmasında bütün hastalara PSG ile Harran Üniversitesi Göğüs Hastalıkları Anabilim Dalında OSAS teşhisi konulmuştur.

OSAS uyku esnasında, üst hava yollarında, çeşitli nedenlerden dolayı meydana gelen tekrarlayıcı daralmalar sonucu oluşan bir durumdur ve OSAS, bireylerin yaşam kalitesini azaltan ve yaşamı tehdit edebilen bir hastalıktı (21). OSAS'ın yetişkin popülasyonu daha fazla oranda etkilediği ve yaş ilerledikçe hastalığın görülme sıklığının arttığı bildirilmektedir (22). Arısoy ve ark. (23) OSAS tanısı almış hastaların özelliklerini inceledikleri çalışmada yaş ortalamasını 51,3 olarak belirtmişlerdir. Doğan ver ark. (24) OSAS klinik şüphesinde hipotiroidizm sıklığını belirlemeyi amaçladıkları çalışmalarında hafif OSAS'lı hastaların yaş ortalamasını 38,25, orta OSAS'ı hastaların yaş ortalamasını 38,91 ve ağır OSAS'lı hastaların yaş ortalamasını 39,89 olarak bulmuşlardır. Alaçam ve ark. (12) ise hafif OSAS'lı hastaların yaş ortalamasını 51,2, orta OSAS'ı hastaların yaş ortalamasını 59,3, ağır OSAS'ı hastaların yaş ortalamasını 50,3 olarak bildirmişlerdir. Bizim çalışmamızda ise OSAS'I hastaların yaş ortalaması 49,63, AHI indeksine göre hafif OSAS'।ı hastaların yaş ortalaması 33,4 , orta OSAS'lı hastaların yaş ortalamasını 49,36 , ağır OSAS'lı hastaların yaş ortalamasını ise 51,84 tür. Hastalık derecesi ile yaş grupları arasındaki ilişki istatistiksel olarak incelendiğinde anlamlı bir ilişki bulunmuştur $(p<0.05)$, ağır OSAS'ı olan hastaların yaş ortalamaları, hafif OSAS'lı hastalara göre anlamlı ölçüde yüksektir. Bu sonuca göre yaş ilerledikçe hastalığın derecesi artmaktadır ve yapıımış olan diğer çalışmalarla uyumludur.
Epidemiyolojik Uyku Çalışması (Episono) verilerine göre, çalışılan kişilerin yaklaşık \% 32'sinde OSAS bulunmaktadır (25). OSAS 30 yıl önce çok nadir görülen bir hastalık olarak kabul edilmiştir (26), ancak son epidemiyolojik çalışmalar şaşırtıcı derecede OSAS prevalansının yüksek olduğunu göstermiştir. AHI $\geqslant 15$ ile tanımlandığı gibi orta yaşlı popülasyonda erkeklerin \%50'sinde ve kadınların \%25'inde orta ila şiddetli OSAS bulunmuştur (27).

Geçtiğimiz 30 yıl boyunca, obezite seviyelerinin dramatik bir şekilde yükselmesi, kısmende olsa OSAS prevalansındaki artışı açıklamıştır (26). Bununla birlikte, artan obezite sadece açıklayıcı değişken olmayabileceği ve puanlama kriterlerindeki değişimlerde OSAS teşhisindeki artışa katkıda bulunabileceği bildirilmiştir (28). İzlanda'da yapılan prevelans çalışmasında orta yaşlı genel popülasyonun, \% 15,4 'ünün $\mathrm{AHI} \geqslant 15$ olduğu ve toplumun \% 3,6'sının zaten OSAS tedavisi aldığı ve bu popülasyonda OSAS prevalansının \%19 olduğu gösterilmiştir (29). Fraklin ve ark. (30) yapmış oldukları çalışmalarında, 1993-2013 yılları arasında yayınlanan ABD, Çin, Japonya, Hindistan, Kore, Japonya ve İsveç'ten 11 nüfus temelli epidemiyolojik çalışma tespit etmişler. AHI $\geq 5$ 'te tanımlanan OSAS prevalansının erkeklerde ortalama $\% 22$ ve kadınlarda $\% 17$ olduğunu belirmişlerdir. Farklı çalışmalarda görülme sıkığı zamanla artmış ve son çalışmalarda OSAS'ın erkeklerin \% 37'sinde ve kadınların\% 50'sinde görüldüğü bildirilmiştir. Zaman içindeki farklııkların AHİ skoru için farklı ekipman, tanımlar, çalışma tasarımı, popülasyonlardaki farklııklar ve artan miktarda obez denekten kaynaklanıyor olabileceği bildirilmiştir (30). Bu araştırma çalışmasında erkek hastaların kadın hastalara oranla daha yüksek olduğu görülmüştür. Erkek hastalar tüm hasta grubunun \% 75,9'unu, kadın hastalar ise \%24,1' ini oluşturmaktadır. Bununla birlikte gruplar arasında OSAS'ın derecesi ile cinsiyet arasında istatistiksel olarak anlamlı ilişki bulunamamıştır. ( $p>0.05)$.

Amerikan Uyku Tıbbı Akademisi'ne göre, uyku bruxism (SB) bir hareket bozukluğu olarak sınıflandırılır ve uyku uyarıma aktivitesiyle ilişkili olarak uyku sırasında dişlerin öğütülmesi veya sıkılması ile karakterize oral bir parafonksiyon olarak tanımlanır (31). Maluly ve ark (32) 1042 birey üzerinde yapmış oldukları çalışmada hastaların \%5.5'nin PSG kriterlerine göre SB olduğunu bildirmişlerdir. Kanadalı bir çalışmada 18-80 yaşları arasındaki bireylerde bu hastalığın prevalansını \%8 olarak bulmuşlardır.(33) Başka birçok merkezli yapılmış olan çalışmada (Ingiltere, Almanya ve İtalya), bu prevalans \% 8,2 olarak bildirilmiştir (34), Kato ve ark. (35), 2012 yılında Japonya'da yapmış oldukları çaış̧mada benzer sonuçları bulmuşlardır. SB ve ritmik çiğneme kası aktivitesinin (RMMA) stres ile modüle olduğu gerçeği ışığında, SB'li bireyler psikolojik strese karşı yüksek hassasiyet gösterirler.(36) Aynı şekilde, psikofizyolojik uykusuzluk, uyku kalitesinin kaybı ile strese verilen tepki ile karakterizedir (37). Maluly (32) ve ark. SB ve insomnia ara- 
sında güçlü bir iliş̧i olduğunu bildirmiştir. Yapmış olduğumuz bu çalışmada toplam 54 OSAS'ı hastanın 13'ünde bruksizm (\%24,1), tanısı konulmuş fakat OSAS'ın derecesi ile bruksizm arasında istatistiksel olarak anlamlı ilişki bulunamamıştır $(p>0.05)$.

\section{Sonuçlar ve Öneriler:}

OSAS erkelerde ve ilerleyen yaşlarda daha yüksek oranda görülmektedir ve yaş ilerledikçe hastalığın şiddetide artmaktadır. Çalışmamızda OSAS'lı hastalarda üçte birinde TME rahatsızlığının eşlik ettiği görülmüş olup en sık gözlenen TME rahatsızlığı grubu olarak bruksizm olduğu kaydedilmiştir. Yazarlar bunun nedeni olarak uyku kalitesinin bozulmasının hastalarda psikolojik strese yol açtığını ve sonuç olarak bruksizmi tetiklediğini düşünmektedir. Bununla birlikte çalışmanın daha geniş hasta popülasyonu üzerinde yapılması ve ayrıca çalışmanın OSAS'lı hastaların tedavi öncesi ve sonrası TME rahatsızlığı bulgularını karşılaştıran ileri çalışmalara intiyaç bulunmaktadır.

\section{Çalışma izni: Çalışma için Harran Üniversitesi Rektörlüğü Araştırma ve Uygulama Hastanesi'nden 01/07/2019- E.27762 tarih ve sayılı çalışma izni alınmıştır.}

\section{Kaynaklar}

1. Odabaş B, Gündüz Arslan S. Temporomandibular eklem anatomisi ve rahatsızlıkları. Dicle Tıp Dergisi. 2008;35:77-85

2. American Academy of Pediatric Dentistry. Clinical guideline on acquired temporomandibular disorders in infants, children and adolescents. Pediatric Dentistry. 2015; 37: 272-8.

3. Liu F, Steinkeler A. Epidemiology, diagnosis, and treatment of temporomandibular disorders. Dent Clin North Am. 2013;57:465-79

4. List T, Dworkin SF. Comparing TMD diagnoses and clinical findings at Swedish and US TMD center using Research Diag-nostic Criteria for Temporomandibular Disorders. J Orofac Pain. 1996;10:240-53

5. Ahmad M, Hollender L, Anderson Q, Kartha K, Ohrbach R, True-love $\mathrm{EL}$, et all. Research diagnostic criteria for temporomandibular disorders (RDC/TMD): development of image analysis criteria and examiner reliability for image analysis. Oral Surg Oral Med Oral Pathol Oral Radiol Endod. 2009;107:844-60

6. Azagra-Calero E, Espinar-Escalona E, BarreraMora JM, Llamas-Carreras JM, Solano-Reina E. Obstructive Sleep Apnea Syndrome (OSAS). Review of the literature. Med Oral Patol Oral Cir Bucal. 2012;17(6):9259

7. Guilleminault C, Tilkian A, Dement WC. The sleep apnea syndromes. Annu Rev Med. 1976;27:465-84.

8. Peppard P E, Young T, Barnet JH, Palta M, Hagen EW, Hla KM. Increased Prevalence of Sleep-Disordered Breathing in Adults. Am J Epidemiol. 2013;177(9):1006-14.

9. Strauss RS, Browner WS. Risk for obstructive sleep apnea. Ann Intern Med. 2000;132(9):758-9.

10. Stansbury RC, Strollo PJ. Clinical manifestations of sleep apnea. J Thorac Dis. 2015;7(9):298-310.

11. Kushida CA, Littner MR, Morgenthaler T, Alessi CA, Bailey D, Coleman J J, et al. Practice parameters for the indications for polysomnography and related procedures: an update for 2005 . Sleep. 2005;28(4):499-521.

12. Alaçam Z, Pekcan S, Akdağ B. Obstrüktif Uyku Apne Sendromu Tanılı Hastalarda; Hemogram Parametreleri ile Gece Desatürasyonu İlişkisi. Journal of Turkish Sleep Medicine. 2018;5:62-6.

13. Jordan AS, McSharry DG, Malhotra A. Adult obstructive sleep apnoea. Lancet. 2014;383:736-47.
14. Okeson JP, de Leeuw R. Differential diagnosis of temporomandibular disorders and other orofacial pain disorders. Dent Clin North Am. 2011;55(1):105-20.

15. Cooper BC, Kleinberg I. Examination of a large patient population for the presence of symptoms and signs of temporomandibular disorders. Cranio. 2007;25(2):114-26.

16. Cunali PA, Almeida FR, Santos CD, Valdrighi NY, Nascimento LS, Dal'Fabbro C, et al. Prevalence of temporomandibular disorders in ob- structive sleep apnea patients referred for oral appliance therapy. J Orofac Pain. 2009;23(4):339-44.

17. Smith MT, Wickwire EM, Grace EG, Edwards RR, Buenaver LF, Peterson $\mathrm{S}$, et al. Sleep disorders and their association with laboratory pain sensitivity in temporomandibular joint disorder. Sleep. 2009;32(6):77990.

18. Sanders AE, Essick GK, Fillingim R, Knott $C$, Ohrbach R, Greenspan JD, Diatchenko L, Maixner W, Dubner R, Bair E, Miller VE, Slade GD. Sleep Apnea Symptoms and Risk of Temporomandibular Disorder: OPPERA Cohort. J Dent Res 2013; Jul;92(7Suppl):70-77.

19. Togeiro SMGP, Smith AK. Diagnostics methods for sleep disorders. Rev Bras Psiquiatr 2005;27(Supl I):8-15.

20. Veiga DM, Cunali R, Bonotto D, Cunali PA. Sleep quality in patients with temporomandibular disorder: a systematic review. Sleep Sci. 2013;6(3):120-124.

21. Pişkin $B$, Akın H, Şentut F. Obstrüktif uyku apnesinde oral aparey kullanımı. Cumhuriyet Dent J 2012;15(3):264-278.

22. Stradling JR, Davies RJO. Obstructive sleep apnea/hypopnea syndrome: definitions, epidemiology and natural history. Thorax. 2004;59(1):73-78.

23. A Arısoy, H Günbatar, S Ekin. OSAS'ı Hastalarımızın Değerlendirilmesi. Van Tip Dergisi. 2014. 21(4): 203-205,

24. D Doğan, N Öcal. Obstruktif Uyku Apne Ön Tanısında Tiroid Fonksiyon Testlerinin Önemi ve Gerekliliği. Konuralp Tıp Dergisi. 2019;11(1): 36-40.

25. Santos-Silva R, Castro LS, Taddei JA, Tufik S, Bittencourt LR. Sleep dis- orders and demand for medical services: evidence from a population- based longitudinal study. PLoS One. 2012;7(2):e30085.

26. Gislason $T$, Sunnergren $O$. Obstructive sleep apnoea in adults. In: Annesi-Maesano I, Lundbäck B and Viegi G, eds. Respiratory Epidemiology (ERS Monograph). Sheffield, European Respiratory Society. 2014;88-105.

27. Heinzer R, Vat $S$, Marques-Vidal P, et al. Prevalence of sleep-disordered breathing in the general population: the HypnoLaus study. Lancet Respir Med. 2015; 3: 310-318.

28. Berry R, Brooks R, Gamaldo C, et al. The AASM Manual for the Scoring of Sleep and Associated Events: Rules, Terminology, and Technical Specifications, Version 2.1. Darien, American Academy of Sleep, 2014.

29. Arnardottir ES, Bjornsdottir E, Olafsdottir KA, Benediktsdottir B, Gislason T. Obstructive sleep apnoea in the general population: highly prevalent but minimal symptoms. Eur Respir J 2016; 47: 194-202.

30. Franklin KA, Lindberg E. Obstructive sleep apnea is a common disorder in the population a review on the epidemiology of sleep apnea. J Thorac Dis 2015;7(8):1311-22.

31. American Academy of Sleep Medicine (2005). The International Classification of Sleep Disorders. Diagnostic and Coding Manual. 2nd ed. Westchester, IL: American Academy of Sleep Medicine.

32. Maluly M, Andersen ML, Dal-Fabbro C, Garbuio S, Bittencourt L, de Siqueira JTT, and Tufik S. Polysomnographic Study of the Prevalence of Sleep Bruxism in a Population Sample. J Dent Res. 2013 Jul;92(7 Suppl):97-103.

33. Lavigne GJ, Montplaisir JY. Restless legs syndrome and sleep bruxism: prevalence and association among Canadians. Sleep 1994;(17):739-43.

34. Ohayon MM, Li KK, Guilleminault C. Risk factors for sleep bruxism in the general population. Chest 2001, 119:53-61.

35. Kato T, Velly AM, Nakane T, Masuda Y, Maki S. Age is associated 
with self-reported sleep bruxism, independently of tooth loss. Sleep Breath 2012,16:1159-65.

36. Abekura H, Tsuboi M, Okura T, Kagawa K, Sadamori S, Akagawa $Y$ (2011). Association between sleep bruxism and stress sensitivity in an experimental psychological stress task. Biomed Res 32:395-399.

37. Bonnet MH, Arand DL (2010). Hyperarousal and insomnia: state of the science. Sleep Med Rev 14:9-15. 